\title{
Correction to: The role of nuclear medicine in assessments of cardiac dyssynchrony
}

\author{
Masanao Naya, MD, PhD, ${ }^{\text {a }}$ Osamu Manabe, MD, PhD, ${ }^{b}$ Kazuhiro Koyanagawa, \\ $M D,{ }^{a}$ and Nagara Tamaki, $M D, P^{c}$ \\ a Department of Cardiovascular Medicine, Hokkaido University Graduate School of Medicine, \\ Sapporo, Japan \\ b Department of Nuclear Medicine, Hokkaido University Graduate School of Medicine, Sapporo, \\ Japan \\ c Department of Radiology, Kyoto Prefectural University of Medicine, Kyoto, Japan
}

doi:10.1007/s12350-017-1113-7

\section{CORRECTION TO: J NUCL CARDIOL \\ HTTPS://DOI.ORG/10.1007/S1 2350-017-1072-Z}

Some of the values in Table 3 of the original publication inadvertently contained discrepancies with the literature from which they were taken. A corrected version of Table 3 can be found below; the values which have been corrected now appear in bold text (row: Romero-Farina G).

\footnotetext{
Electronic supplementary material The online version of this article (https://doi.org/10.1007/s12350-017-1113-7) contains supplementary material, which is available to authorized users.

The original article can be found online at https://doi.org/10.1007/ s12350-017-1072-z.

Reprint requests: Masanao Naya, MD, PhD, Department of Cardiovascular Medicine, Hokkaido University Graduate School of Medicine, Kita-15, Nishi-7, Kita-ku, Sapporo 060-8638, Japan; naya@med.hokudai.ac.jp

J Nucl Cardiol 2018;25:1988-9.

$1071-3581 / \$ 34.00$

Copyright (c) 2017 American Society of Nuclear Cardiology. 


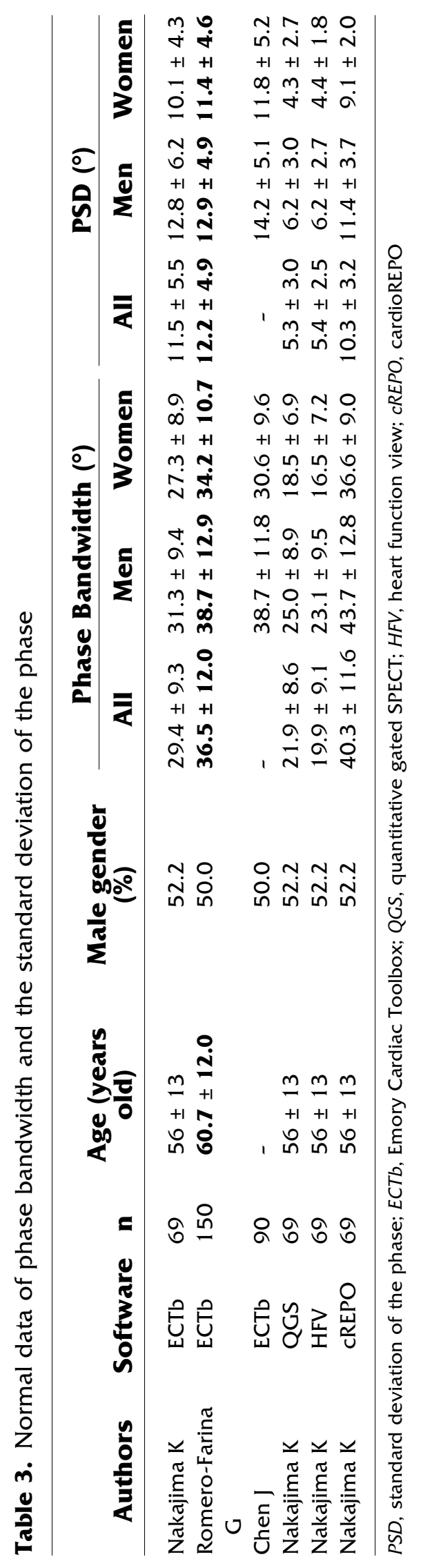

